\title{
Mutation of the WI-1 gene yields an attenuated Blastomyces dermatitidis strain that induces host resistance
}

\author{
Marcel Wüthrich, ${ }^{1}$ Hanna I. Filutowicz, ${ }^{1}$ and Bruce S. Klein ${ }^{1,2,3,4}$ \\ ${ }^{1}$ Department of Pediatrics, \\ ${ }^{2}$ Department of Internal Medicine, \\ ${ }^{3}$ Department of Medical Microbiology and Immunology, and \\ ${ }^{4}$ The Comprehensive Cancer Center, University of Wisconsin Medical School, University of Wisconsin Hospital and Clinics, \\ Madison, Wisconsin, USA \\ Address correspondence to: Bruce S. Klein, University of Wisconsin-Madison, \\ 600 Highland Avenue, Room K4/434, Madison, Wisconsin 53792, USA. \\ Phone: (608) 263-9217; Fax: (608) 263-0440; E-mail: bsklein@facstaff.wisc.edu. \\ This work was presented in part at the 100th General Meeting of the American Society for Microbiology in Los Angeles, California, \\ USA in May, 2000. Portions of this work have appeared in abstract form (Session no. 106, abstract no. F-34, p. 326). \\ Received for publication August 11, 2000, and accepted in revised form October 23, 2000.
}

Systemic fungal infections are becoming more common and difficult to treat, and vaccine prevention is not available. Pulmonary infection with the dimorphic fungus Blastomyces dermatitidis often progresses and requires treatment to prevent fatality. We recently created a recombinant strain of the fungus lacking the WI-1 adhesin and pathogenicity. We show here that administration of viable yeast of this attenuated strain vaccinates against lethal pulmonary experimental infection due to isogenic and nonisogenic strains from diverse geographic regions. To our knowledge, this is the first example of a recombinant attenuated vaccine against fungi. The vaccine induces delayed-type hypersensitivity and polarized type 1 cytokine responses, which are linked with resistance. A cell-wall/membrane $(\mathrm{CW} / \mathrm{M})$ antigen from the vaccine strain also induces polarized and protective immune responses. Lymph node cells and $\mathrm{CD} 4^{+} \mathrm{T}$-cell lines raised with $\mathrm{CW} / \mathrm{M}$ antigen transfer protective immunity when they release type 1 cytokine IFN- $\gamma$, but not when they release IL-4, and neutralization of IFN- $\gamma$ confirmed its role in vivo. Thus, by mutating a pathogenetic locus in a dimorphic fungus, we have created an attenuated vaccine strain and have begun to elucidate fungal and host elements requisite for vaccine immunity.

J. Clin. Invest. 106:1381-1389 (2000).

\section{Introduction}

The systemic dimorphic fungus Blastomyces dermatitidis produces a progressive pulmonary and disseminated infection and is one of the principal systemic mycoses of humans and animals worldwide. Infections that go undiagnosed or untreated often progress and become fatal even in immunocompetent hosts. The progressive nature of many clinical $B$. dermatitidis infections distinguishes blastomycosis from several other related mycoses such as histoplasmosis, coccidioidomycosis, and paracoccidioidomycosis, which more often occur as self-limited infections. A murine model of $B$. dermatitidis infection has been developed that resembles clinical features of pulmonary blastomycosis in people $(1,2)$. Administration of $B$. dermatitidis via the respiratory route, with as few as 10-100 virulent yeast, leads to chronic, progressive pneumonia, which consumes mice within several weeks of infection (3). Thus, even a small number of $B$. dermatitidis yeast cannot be resolved by an immunocompetent host.

Antigens that stimulate clearance of $B$. dermatitidis infection have not been identified. WI-1, a surface protein adhesin on $B$. dermatitidis, is an immunodominant antigen that evokes humoral and cell-mediated immune responses in infected humans (4-6), dogs (7), and mice (2). Immunization of mice with WI-1 elicits immune responses and enhances resistance against lethal pulmonary infection (2). Although WI-1 immunization prolongs survival of mice in a model of lethal pulmonary blastomycosis, the biologic effect is modest. Immunized mice live 1-2 weeks longer than do nonimmunized controls, but most immunized mice succumb to infection. Thus, immune responses to antigens other than WI-1 may be important for protective immunity.

Homologous gene targeting and disruption of WI-1 renders $B$. dermatitidis yeast unable to establish a lethal pulmonary infection (3). On histological inspection, animals infected with wild-type $B$. dermatitidis strain ATCC 26199 (American Type Culture Collection, Rockville, Maryland, USA) show pulmonary alveoli obliterated with inflammation and yeast, whereas mice infected with recombinant WI-1 knockout strain no. 55 show largely normal appearing lungs, with focal, wellformed granulomas containing few sequestered organisms. Hence, the multiplication of recombinant, WI-1 
knockout strain no. 55 is controlled, and the histological appearance of infected tissue implies that the organism has elicited acquired immunity. These findings suggest that a recombinant, attenuated strain, such as strain no. 55, might vaccinate against pulmonary blastomycosis.

We tested that possibility and report here a recombinant, live, attenuated vaccine against $B$. dermatitidis. The vaccine induces a polarized type 1 cytokine profile linked with resistance. A cell-wall membrane $(\mathrm{CW} / \mathrm{M})$ antigen of the vaccine strain independently induces polarized and protective immune responses. $\mathrm{CD}^{+} \mathrm{T}$-cells that recognize this protective antigen transfer resistance to naive mice when they release IFN- $\gamma$, but not when they instead release IL-4. Finally, neutralization of IFN- $\gamma$ in vivo confirmed its requisite role in vaccine-induced resistance.

\section{Methods}

Fungal strains and growth conditions. Strains used included ATCC 26199, a virulent strain isolated from a human patient in South Carolina (1) and an isogenic, nonpathogenic mutant of 26199 lacking WI-1, designated strain no. 55. Details about generation, characterization, and pathogenicity of recombinant strain no. 55 have been described (3). Also included were ATCC 60636 , isolated from soil and patients during a Wisconsin outbreak of blastomycosis (8); ATCC 60637, isolated from soil at the Tomorrow River in Wisconsin (9); ATCC 66136, a soil isolate from Ontario, Canada (10); SC 89, a patient isolate from South Carolina (A.F. Di Salvo, State Health Lab, Reno, Nevada, USA); and SC 396, a soil isolate from Georgia (11). Isolates were maintained in yeast form on Middlebrook 7H10 agar slants with oleic acid-albumin complex (Sigma Chemical Co., St. Louis, Missouri, USA) at $37^{\circ} \mathrm{C}$. Liquid cultures of yeast were grown in Histoplasma macrophage medium (HMM) $(12,13)$ in a $37^{\circ} \mathrm{C}$ shaking incubator.

Mouse strains. Inbred C57BL/ 6 and BALB/c strains of mice were obtained from The Jackson Laboratory (Bar Harbor, Maine, USA). Male mice were 6-7 weeks of age at the time of purchase and were housed and cared for according to guidelines of the University of Wisconsin Animal Care Committee, which approved this work.

Immunization with recombinant, live, attenuated strain no. 55. Mice were injected with $10^{4}$ yeast in PBS $(10 \mathrm{mM}$ sodium phosphate, $154 \mathrm{mM}$ sodium chloride [ $\mathrm{pH}$ 7.4]) by different routes, intranasally, subcutaneously, or intravenously. Mice were boosted with the same number of yeast 2 weeks later. After initial studies demonstrated that the subcutaneous route of immunization was most effective, subsequent experiments used this route. Mice were immunized twice, 2 weeks apart, each time receiving subcutaneous injection of $10^{5}$ no. 55 yeast at each of two sites, dorsally and at the base of the tail.

Delayed-type bypersensitivity. Two weeks after vaccination, delayed-type hypersensitivity (DTH) was measured by injection of $10^{5}$ heat-killed no. 55 yeast into the footpad of one hind leg and PBS as a control into the footpad of the other hind leg. Footpad swelling was measured 24 hours after injection. DTH was defined as swelling due to yeast minus that due to PBS, expressed in millimeters.

Proliferation assays, production of culture supernatants, and cytokine measurements. Single-cell suspensions were prepared from spleens of mice as described elsewhere (14). Suspensions were made in ice-cold culture medium (DMEM containing 10\% FBS, 16 mM HEPES buffer, 2 $\mathrm{mM}$ L-glutamine, and $100 \mathrm{U} / \mathrm{ml}$ penicillin, and 100 $\mu \mathrm{g} / \mathrm{ml}$ streptomycin). Staining of cells with trypan blue indicated greater than $95 \%$ viability.

Spleen cells were stimulated at a concentration of $5 \times 10^{6}$ cells $/ \mathrm{ml}$ in $5 \mu \mathrm{g} / \mathrm{ml}$ of mitogen concanavalin A (CON A) or $12.5 \mu \mathrm{g} / \mathrm{ml}$ of yeast antigen. To measure proliferation, $1 \times 10^{6}$ spleen cells were cultured in vitro in $200 \mu \mathrm{l}$ of medium in 96 well plates. After 72 hours of incubation at $37^{\circ} \mathrm{C}$, in $5 \% \mathrm{CO}_{2}, 1 \mu \mathrm{Ci} /$ well of $\left[{ }^{3} \mathrm{H}\right] \mathrm{TdR}$ was added to each well. After 18 hours, cells were harvested onto glass fiber filters with an automated cell harvester (Matrix 9600; Packard Instruments, Downers Grove, Illinois, USA) and counts per minute of label incorporated into DNA of cells was measured in a gamma counter.

Cells-culture supernatants were generated in 24-well plates in a volume of $1 \mathrm{ml}$ containing $5 \times 10^{6}$ spleen cells. Cells were cultured with antigen or mitogen at concentrations noted previously here. Supernatants were harvested after 48 hours and 96 hours of coculture. ELISA kits were used to measure IL-2 and IL-4 (PharMingen, San Diego, California, USA) and IFN- $\gamma$ (R\&D Systems Inc., Minneapolis, Minnesota, USA). ELISAs were developed with Vectastain ABC-AP (Ak-5000; Vector Laboratories, Burlingame, California, USA) and alkaline phosphatase substrate $\mathrm{p}$-Nitrophenyl phosphate disodium hexahydrate (Sigma Chemical Co.). Optical density (405 $\mathrm{nM}$ ) of wells was measured with an automatic plate reader (Spectra Max 190; Molecular Devices Corp., Sunnyvale, California, USA).

Preparation and administration of antigens of recombinant strain no. 55. Antigens were extracted from yeast cells of strain no. 55 according to the method of Gomez et al. (15). Briefly, yeast were grown in liquid HMM for 5 days. Harvested cells were killed in thimerosal $(1: 10,000 \mathrm{wt} / \mathrm{vol})$ in $\mathrm{PBS}(\mathrm{pH} 7.2)$ for 1 hour at $37^{\circ} \mathrm{C}$ followed by overnight incubation at $4^{\circ} \mathrm{C}$. Washed, pelleted cells were suspended in PBS containing $1 \mathrm{mM}$ phenylmethylsulfonyl fluoride, $5 \mu \mathrm{M}$ leupeptin and 5 $\times 10^{-4} \mathrm{M}$ sodium EDTA. Cells were disrupted (Braun Biotech, Allentown, Pennsylvania, USA) at $4^{\circ} \mathrm{C}$ for 2 minutes using alternating 30 -second cycles of homogenization and cooling. Disrupted cells were centrifuged, and supernatant was saved and termed yeast cytosol extract (YCE). Pelleted cell walls were extracted with urea (15). Supernatant was saved and termed $\mathrm{CW} / \mathrm{M}$ extract. Antigen preparations were dialyzed against PBS, centrifuged at $31,000 \mathrm{~g}$ for 30 minutes. Soluble material was sterilized with a $0.2-\mu \mathrm{m}$ filter and stored at $-20^{\circ} \mathrm{C}$. 
Yeast surface proteins (YSP) also were extracted. Freshly harvested yeast of strain no. 55 were boiled in $\mathrm{H}_{2} \mathrm{O}(1$ volume cells +2 volume $\mathrm{H}_{2} \mathrm{O}$ ) for 5 minutes. The extract was cooled on ice, vortexed for 1 minute, and centrifuged twice at $8,000 \mathrm{~g}$ for 5 minutes each. Extract was sterilized with a $0.2-\mu \mathrm{m}$ filter, and stored at $-20^{\circ} \mathrm{C}$.

C57BL6 mice were immunized subcutaneously at two sites, dorsally and at the base of the tail, with antigen, using $200 \mu \mathrm{g}$ of protein per injection. Antigen was emulsified in CFA (Sigma Chemical Co.) for the first immunization and in incomplete Freund's adjuvant for the second immunization 2 weeks later. Control mice received an equal volume of PBS emulsified in adjuvant. Antigen-specific T-cell lines. C57BL6 mice were immunized subcutaneously with strain no. 55 yeast given in two locations, dorsally and at the base of the tail, three times, 2 weeks apart each. Two weeks after immunization, mice received $200 \mu \mathrm{g}$ of CW/M emulsified in complete Freund's adjuvant administered into the base of the tail and both foot pads of hind legs. After ten days, draining lymph node cells were removed and cultured in medium (as described here, and also containing $0.12 \mathrm{mg} / \mathrm{ml} \mathrm{L}$-arginine, $0.035 \mathrm{mg} / \mathrm{ml}$ L-asparagine, $1 \mathrm{mM}$ MEM sodium pyruvate, $0.6 \mathrm{mg} / \mathrm{ml}$ folic acid, and $5.5 \times 10^{-5} \mathrm{M} 2$-mercaptoethanol) at the concentration of $2 \times 10^{6} \mathrm{cells} / \mathrm{ml}$ with $6 \times 10^{6} / \mathrm{ml}$ syngeneic, irradiated $(1,800 \mathrm{R})$ spleen cells as antigen-presenting cells and $12.5 \mu \mathrm{g} / \mathrm{ml}$ of CW/M antigen. Stimulated cells were harvested 8 days later, and cultured at $2 \times 10^{5}$ cells $/ \mathrm{ml}$ in the presence of antigen and $2 \times 10^{6}$ antigen presenting cells $/ \mathrm{ml}$ in a 24 -well plate. To maintain this T-cell line, cells were restimulated every 2 weeks with fresh $\mathrm{CW} / \mathrm{M}$ antigen and antigen-presenting cells. T cells from the line were $96 \% \mathrm{CD}^{+}, \mathrm{CD}^{+}$; they proliferated in vitro specifically in response to stimulation with $\mathrm{CW} / \mathrm{M}$, and released IL-4, but not IFN- $\gamma$. The line is designated CW/M-Th2.

To generate a T-cell line with a polarized type 1 cytokine response, mice were immunized and draining lymph node cells were cultured in vitro as previously described here, with a modification. Culture medium was supplemented with $10 \mathrm{U} / \mathrm{ml}$ human rIL-2, $1 \mu \mathrm{g} / \mathrm{ml}$ rat anti-mouse IL-4 mAb (a gift from C. Reynolds, Biological Resources Branch, Frederick, Maryland, USA) and $600 \mathrm{U} / \mathrm{ml}$ murine rIFN- $\gamma$ (PharMingen). A resulting line, designated CW/M-Th1, was $97 \% \mathrm{CD}^{+}$, $99 \%$ $\mathrm{CD}^{+}$; it proliferated in vitro specifically on stimulation with $\mathrm{CW} / \mathrm{M}$ antigen, and released IFN- $\gamma$, but not IL-4. After eight rounds of stimulation, CW/M-Th1 maintained its phenotype without addition of rIFN- $\gamma$, anti-IL-4 mAb, and r-IL-2 (data not shown). In vitro analyses of CW/M-Th1 were done in the absence of exogenous IL-2, anti-IL-4 mAb, or IFN- $\gamma$.

IFN- $\gamma$ nentralization. Ammonium sulfate-precipitated mAb XMG1.2 (anti-IFN- $\gamma$ ) was kindly provided by G.S. Deepe (Cincinnati, Ohio, USA). Six hours before infection, mice received $0.5 \mathrm{mg} \mathrm{mAb}$ intravenously in $0.5 \mathrm{ml}$ PBS. Mice were boosted with $0.5 \mathrm{mg} \mathrm{mAb}$ intraperitoneally every 4 days. Control mice received equivalent amounts of rat IgG (Sigma Chemical Co.).
Experimental infection. Mice were infected intratracheally with $B$. dermatitidis yeast as described later here, although in some initial experiments, mice were infected intranasally (2). For intratracheal infection, mice were anaesthetized by intraperitoneal injection of etomidate $(30 \mathrm{mg} / \mathrm{kg}$; Bedford Laboratories, Bedford, Ohio, USA). Skin over the trachea was incised and underlying tissue separated. A 30-gauge needle (Becton Dickinson, Rutherford, New Jersey, USA) was bent and attached to a tuberculin syringe containing $B$. dermatitidis yeast. The needle was inserted into the trachea, and $30 \mu \mathrm{l}$ of inoculum was dispensed using a stepper device (Tridak, Brookfield, Connecticut, USA). Incised skin was closed with cyanoacrylate adhesive (Veterinary Products Laboratories, Phoenix, Arizona, USA). Mice recovered under a heating lamp. To assess vaccine efficacy, two outcomes were measured. Lung infection was quantified by plating homogenized lung and enumerating yeast CFUs on brain-heart infusion (Difco Laboratories, Detroit, Michigan, USA) agar. Lung CFU for a mouse was defined as total CFU per lung. Detection limit was $10 \mathrm{CFU}$ per lung. Alternatively, duration of survival was monitored.

Statistical analysis. Kaplan Meier (16) survival curves were generated for infected mice. Survival times of mice that were alive by the end of the study were regarded as censored. Time data were analyzed by the log rank statistic (Mantel-Haenszel test) (17), and exact $P$ values were computed using the statistical packaged Stat Xact-3 software (CYTEL Software Corp., Cambridge, Massachusetts, USA). Differences in number of CFU were analyzed using the Wilcoxon rank test for nonparametric data (16). A two-sided $P$ value of less than 0.05 is considered statistically significant.

\section{Results}

Administration of recombinant strain no. 55 protects mice against pulmonary blastomycosis. The evolution of experimental pulmonary blastomycosis is shown for nonimmune mice in Figure 1, b and c, and illustrates unchecked multiplication of yeast in lungs, progressive pneumonia, and death. In contrast, targeted disruption of the WI-1 adhesin abolishes pathogenicity of $B$. dermatitidis in this murine model of pulmonary infection and leads to clearance of yeast from lung (3). We tested here whether clearance of WI-1 knockout strain no. 55 induces immunity and vaccinates against wild-type $B$. dermatitidis infection. Naive C57BL/ 6 mice received two injections of strain no. 55 yeast either intranasally or subcutaneously, or three injections by multiple routes, intranasally, subcutaneously, and intravenously, with each injection spaced 2 weeks apart. After immunization, mice were analyzed for evidence of immunity and resistance to experimental $B$. dermatitidis infection.

Immunization subcutaneously or by the combined route prompted strong DTH, whereas immunization intranasally yielded marginal DTH (Figure 1a). Immunized mice were challenged with the parent wild-type strain ATCC 26199. At 3 weeks after infection, lung 

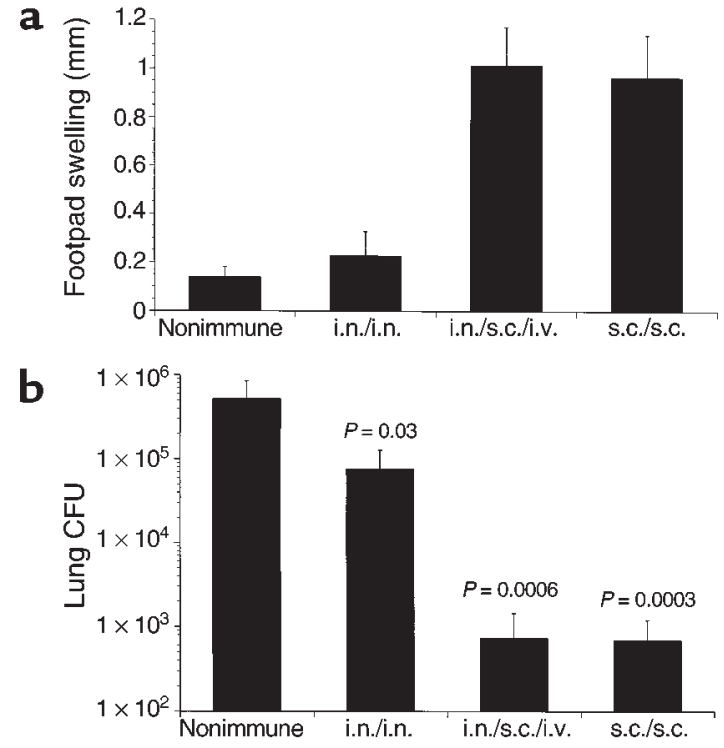

C

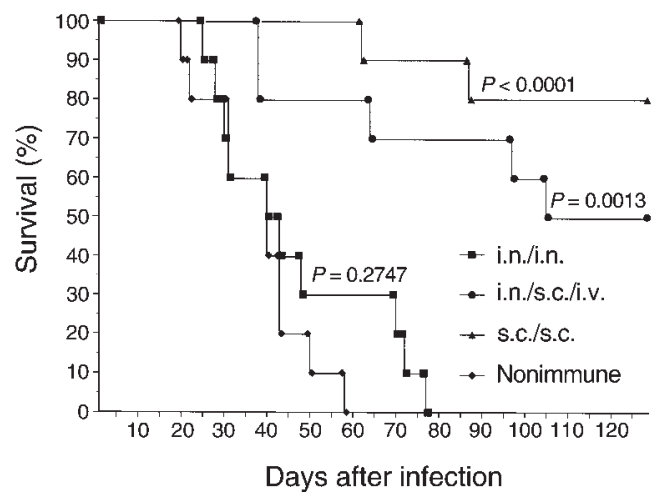

Figure 1

Acquired resistance to blastomycosis after vaccination with a recombinant, live, attenuated strain of $B$. dermatitidis. (a) DTH responses. C57BL/ 6 mice were vaccinated by different routes: intranasal (i.n.), subcutaneous (s.c.), and intravenous (i.v.). After immunization, groups of four mice were injected with $10^{5}$ dead yeast of strain no. 55 into one footpad or PBS into the other. Footpad swelling was measured 24 hours later. Error bars are SEM. (b) Burden of lung infection. Two weeks after immunization, groups of 10 mice were infected intranasally with $10^{4} 26199$ wild-type yeast. Three weeks later, mice were analyzed for lung CFU. Geometric means of CFUs were calculated. Error bars are SEM. $P$ values are for comparison of each immunized group versus nonimmune controls. (c) Survival after infection. Groups of ten C57BL/ 6 mice were infected as in $\mathbf{b}$ and monitored for survival over 128 days. $P$ values are for comparison of each immunized group versus nonimmune mice.

CFU was reduced significantly in all immunized groups versus controls (Figure 1b). Immunization subcutaneously or by the combined route reduced lung $\mathrm{CFU}$ by between two to three logs versus controls. Immunization intranasally reduced lung CFU marginally, but significantly, versus controls.

In survival studies, $80 \%$ of mice immunized subcutaneously and 50\% immunized by the combined route lived for 128 days and did not appear ill at the end of the experiment (Figure 1c). When surviving mice were analyzed, six of eight immunized subcutaneously and all five immunized by the combined route had no detectable yeast in their lungs. Although results shown in Figure 1 are for C57BL/ 6 mice; similar results were observed in $\mathrm{BALB} / \mathrm{c}$ mice (data not shown). For studies described later here, we vaccinated C57BL/ 6 mice by subcutaneous administration of attenuated strain no. 55 .

Recombinant strain no. 55 is localized at the vaccine site, but isogenic wild-type yeast disseminate. We investigated whether vaccination requires attenuated strain no. 55 or if it can be accomplished with the wild-type parental yeast. Strains 26199 and no. 55 were administered subcutaneously at two sites, twice, 2 weeks apart at doses of $10^{5}, 10^{6}$, and $10^{7}$ yeast, and dissemination to lung, liver, spleen and brain was assessed. Six weeks after initial injection, nine of ten mice that had received $10^{7}$ wildtype yeast showed dissemination of infection to the lung (mean CFU, 205,600 $\pm 194,840$ ). Several of these mice were ill with poor coat, weight loss, and hunched posture, and it was clear that they would die of infection; two with $1,864,000$ and 149,000 lung $\mathrm{CFU}$, respectively, appeared moribund. Only one of ten mice injected with $10^{7}$ isogenic strain no. 55 yeast had dissemination to lung; that animal had $50 \mathrm{CFU}$ and did not appear ill. For lower vaccine doses of $10^{6}$ and $10^{5}$, four of ten mice that received wild-type yeast, at either dose, showed dissemination to lung; the groups had mean CFU values of 3,420 $\pm 2,549$ and 8,193 $\pm 8,226$, respectively. One mouse that received $10^{5}$ wild-type yeast showed advanced lung infection with 78,400 CFU. In contrast, none of the mice injected with strain no. 55 at either of these two doses had dissemination to lung. Neither strain disseminated to liver, spleen, or brain. For vaccinations described later here, we administered $10^{5}$ yeast of strain no. 55 per injection.

Optimal form and schedule for administration of recombinant, attenuated strain no. 55. To optimize vaccination, we tested whether viability of yeast and immunization schedule influenced resistance. Vaccination twice, 2 weeks apart, with live yeast reduced lung CFU significantly more than did vaccination with dead yeast (mean, $110 \pm 90$ vs. $3,560 \pm 4,320 ; P=0.0009$ ), although the latter also reduced lung CFU compared with nonimmune mice (mean, $113,500 \pm 64,400 ; P=0.039$ ). Additionally, two vaccinations reduced lung CFU significantly more than did one vaccination (mean, $54 \pm 34$ vs. $12,300 \pm 8,300 ; P=0.0004$ ), although the latter also reduced lung CFU compared with nonimmune mice (mean, 476,900 $\pm 171,700 ; P=0.0008)$. A third vaccination added no benefit (data not shown). Thus, for studies shown later here, we vaccinated subcutaneously with $2 \times 10^{5}$ live yeast of strain no. 55 , divided at two sites, given twice, 2 weeks apart.

Vaccination with strain no. 55 cross-protects against infection with nonisogenic strains. So far, vaccination with recombinant attenuated strain no. 55 has protected against reinfection with the wild-type isogenic strain ATCC 26199, a patient isolate from South Carolina. We wondered whether strain no. 55 vaccine resistance would crossprotect against infection with nonisogenic strains, and 
Table 1

Vaccination with recombinant live attenuated strain no. 55 crossprotects against experimental pulmonary infection with five other nonisogenic isolates of $B$. dermatitidis

\begin{tabular}{|c|c|c|}
\hline Groups ${ }^{A}$ & Lung CFUB & Significanc \\
\hline \multicolumn{3}{|l|}{ ATCC 60636} \\
\hline $\begin{array}{l}\text { Nonimmune } \\
\text { Immune }\end{array}$ & $\begin{array}{c}4,885,000 \pm 908,700 \\
10,260 \pm 9,940\end{array}$ & 0.0002 \\
\hline \multicolumn{3}{|l|}{ ATCC 60637} \\
\hline $\begin{array}{l}\text { Nonimmune } \\
\text { Immune }\end{array}$ & $\begin{aligned} 2,449,400 & \pm 291,000 \\
14,700 & \pm 20,500\end{aligned}$ & 0.0004 \\
\hline \multicolumn{3}{|l|}{ ATCC 66136} \\
\hline $\begin{array}{l}\text { Nonimmune } \\
\text { Immune }\end{array}$ & $\begin{array}{c}252,500 \pm 37,800 \\
200 \pm 210\end{array}$ & 0.0004 \\
\hline \multicolumn{3}{|l|}{ SC89 } \\
\hline $\begin{array}{l}\text { Nonimmune } \\
\text { Immune }\end{array}$ & $\begin{aligned} 6,226,500 & \pm 3,443,400 \\
2,390 & \pm 2,530\end{aligned}$ & 0.0004 \\
\hline \multicolumn{3}{|l|}{ SC396 } \\
\hline $\begin{array}{l}\text { Nonimmune } \\
\text { Immune }\end{array}$ & $\begin{array}{c}1,582,400 \pm 717,300 \\
1\end{array}$ & 0.0002 \\
\hline
\end{tabular}

AMice were immunized subcutaneously by injecting live yeast of strain no. 55 yeast twice, 2 weeks apart. Nonimmune control mice were nonimmunized. Two weeks after immunization, animals were infected intratracheally with $10^{2}$ yeast of the indicated nonisogenic strain. Three weeks later, mice were analyzed for burden of lung infection. ${ }^{\mathrm{B}}$ Lung CFU are calculated as the geometric mean of ten mice per group \pm SEM.

tested immunized mice for resistance to five such strains of $B$. dermatitidis from different geographical regions. All five strains were found to be virulent and killed mice by 3 weeks after infection (data not shown). Mice that were immunized with vaccine strain no. 55 and then challenged with any of the nonisogenic strains had markedly lower lung CFU (two to six logs) compared with nonimmune controls (Table 1 ).

Immunization with recombinant strain no. 55 evokes a polarized type 1 cytokine profile. We analyzed immune responses associated with vaccine resistance. Before infection, splenocytes from immunized mice proliferated and produced type 1 cytokines IL- 2 and IFN- $\gamma$ in response to $\mathrm{CW} / \mathrm{M}$ antigen of strain no. 55 (Figure 2, $\mathrm{a}-\mathrm{c})$. Splenocytes of nonimmune mice did not proliferate or produce these cytokines in response to the antigen, but they did in response to CON A. After infection, splenocytes from immunized mice again proliferated and made elevated amounts of IL- 2 and IFN- $\gamma$ in response to the antigen (Figure 2, d-f). Splenocytes from nonimmunized mice proliferated weakly in response to the antigen, but still did not release IL-2 and IFN- $\gamma$ except in response to CON A. IL-4, a type 2 cytokine, was never detected from immune or nonimmune splenocytes stimulated with $\mathrm{CW} / \mathrm{M}$, but was detected in response to CON A (data not shown).

Immunization with cell-wall antigens of recombinant strain no. 55 evokes type 1 cytokines and protects against infection. Because a CW/M antigen stimulated release of type 1 cytokines from splenocytes of vaccinated mice, we tested whether this antigen or others made here immunized mice and protected against infection. SDS-PAGE showed that the three antigens had multiple constituents, ranging widely in molecular weight, although YSP had major constituents of 50-60 kDa (Figure 3a).

Immunization with all three crude antigens evoked type 1 cytokine responses detectable before infection (data not shown) and afterward (Figure 3b). Splenocytes of mice immunized with $\mathrm{CW} / \mathrm{M}$ produced the strongest IFN- $\gamma$ and IL-2 response in vitro on stimulation with antigen. Splenocytes of mice immunized with one antigen also released type 1 cytokine on exposure to the other two antigens, implying that the preparations contain overlapping components. No IL-4 was detected when splenocytes from any immunized group were cultured in the presence of antigen, whereas CON A evoked IL-4 release from these cells, as already described (data not shown). Splenocytes from nonimmunized, infected mice produced undetectable IFN- $\gamma$, but they did release small amounts of IL-2 after in vitro exposure to the antigens.

Immunization with each antigen sharply reduced lung infection (Figure 3c). CW/M was most protective and reduced lung CFU three logs in immunized mice versus nonimmunized controls. Immunization with each antigen also increased survival (Figure 3d). At 165 days after infection, nonimmunized controls had expired, but $40 \%$ of mice that got YSP, $70 \%$ that got $\mathrm{CW} / \mathrm{M}$, and $100 \%$ that got YCE were alive and appeared healthy. Survivors were analyzed for residual lung infection. All four YSP-immunized mice, seven of nine YCEimmunized mice, and five of seven CW/M-immunized mice had no detectable lung CFU. Thus, most survivors had sterilizing immunity.
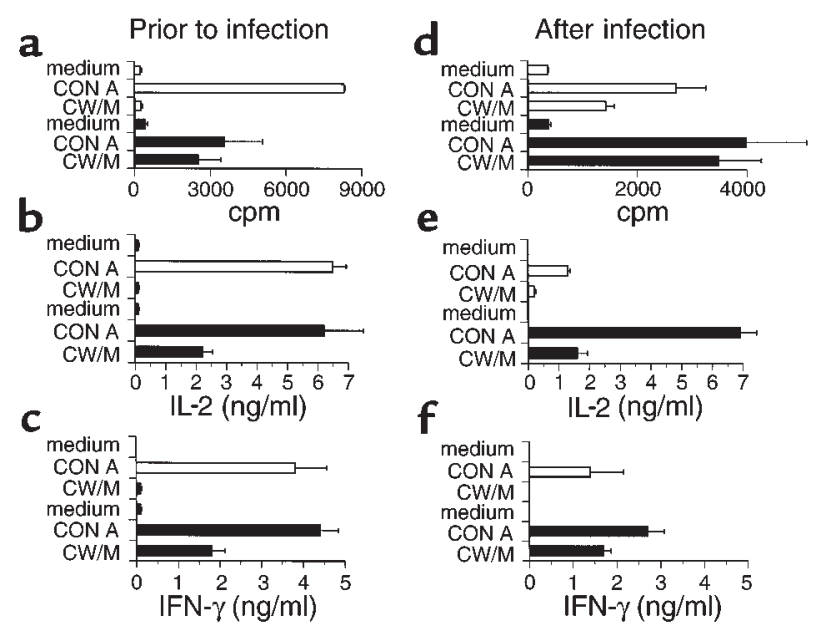

Figure 2

Immune responses of vaccinated mice. Splenocytes from nonimmune mice (open bars) and immunized mice (filled bars) were cocultured at $5 \times 10^{6}$ cells $/ \mathrm{ml}$ with medium alone, CON A (5 $\mu \mathrm{g} / \mathrm{ml})$, or $\mathrm{CW} / \mathrm{M}$ antigen $(12.5 \mu \mathrm{g} / \mathrm{ml})$. Data are mean values of four independent experiments. ( $\mathbf{a}$ and $\mathbf{d}$ ) Proliferation was measured as cpm of $\left[{ }^{3} \mathrm{H}\right] \mathrm{TdR}$ incorporated into proliferating cells after 4 days of coculture. ( $\mathbf{b}$ and $\mathbf{c}$ ) Before infection with $B$. dermatitidis, IL-2 and IFN- $\gamma$ were measured in supernates of splenocytes, cultured as described in the text. (e and $\mathbf{f}$ ) After infection with B. dermatitidis, studies were performed as in $\mathbf{b}$ and $\mathbf{c}$. 

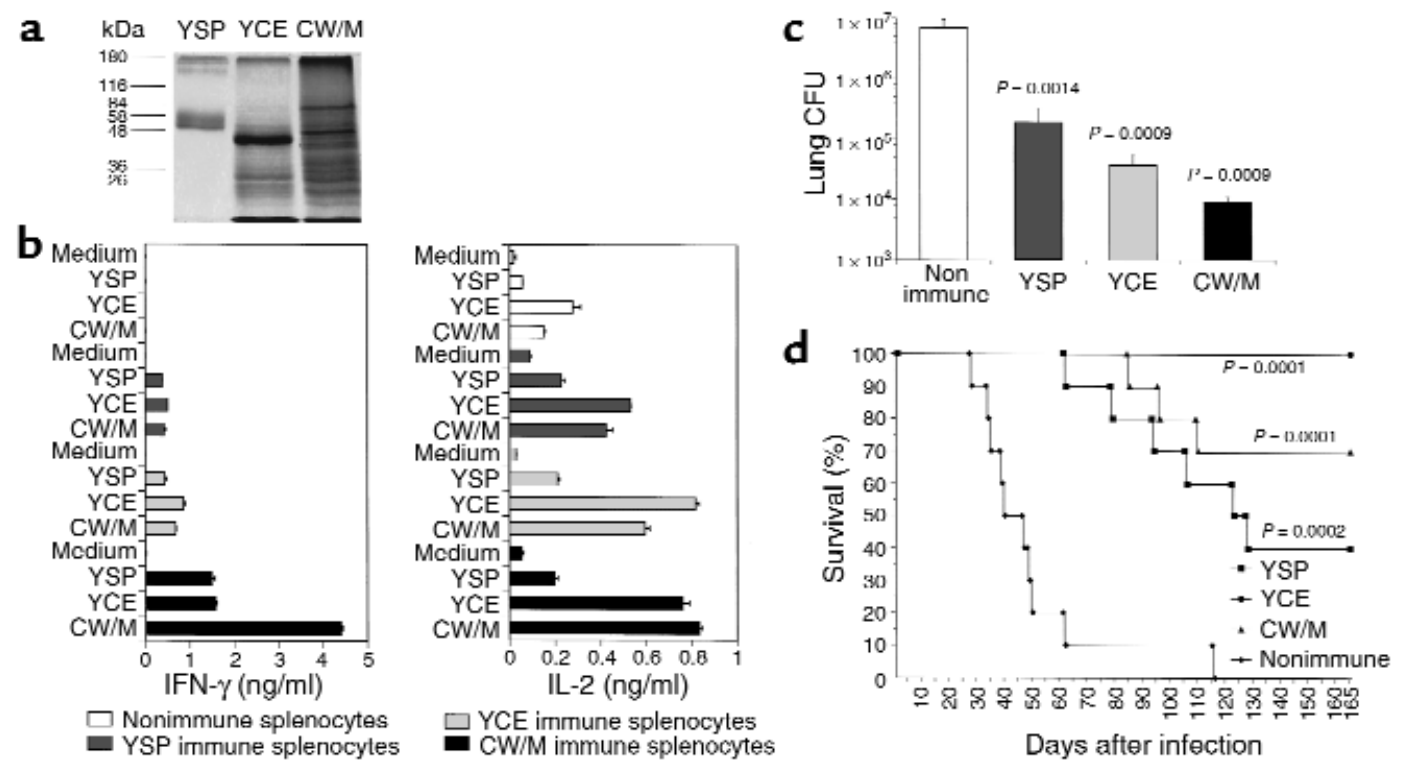

\section{Figure 3}

Immunogenicity and protective efficacy of antigens of recombinant attenuated strain no. 55. (a) SDS-PAGE of soluble antigens prepared from recombinant, attenuated strain no. 55. Antigens are CW/M, YSP, and YCE. A total of $100 \mu \mathrm{g}$ of protein for CW/M and YCE and $50 \mu \mathrm{g}$ for YSP was loaded per lane and run on a 10\% acrylamide gel under reducing conditions. Molecular weight markers (Mr) are depicted. (b) Cytokine production by splenocytes in vitro after immunization with antigen. Three weeks after infection, splenocytes from immunized and control mice were harvested and cultured $\left(5 \times 10^{6}\right.$ cells $\left./ \mathrm{ml}\right)$ in the presence of antigens $(12.5 \mu \mathrm{g} / \mathrm{ml})$ described in a. Culture supernatants were harvested after incubation for 48 hours and 96 hours and analyzed for IFN- $\gamma$ ( 96 hours) and IL-2 (48 hours) by ELISA. Detection limit of $0.05 \mathrm{ng} / \mathrm{ml}$ for each. (c) Burden of lung infection. Groups of 10 C57BL/ 6 mice were immunized with $400 \mu \mathrm{g}$ antigen in Freund's adjuvant twice, 2 weeks apart; infected intratracheally with $10^{2} 26199$ wild-type yeast; and analyzed for lung CFU three weeks after infection. Values depicted are geometric mean CFUs \pm SEM. $P$ values are for each group in relation to nonimmune controls. (d) Survival after infection. Groups of 10 C57BL/ 6 mice were infected as in $\mathbf{c}$ and monitored for survival over 165 days. $P$ values are for comparison of each immunized group versus nonimmune mice.

Adoptive transfer of protective immunity by lymphoid cells reactive with $C W / M$. We investigated the lymphoid compartment in which protective cells reside, to isolate and analyze them. Mice were vaccinated three times with strain no. 55, 2 weeks apart. Subsequently, they received $200 \mu \mathrm{g}$ soluble CW/M or YSP antigen once as detailed in Methods. Ten days after immunization, splenocytes and draining lymph node cells were collected for functional analysis. Lymphoid populations of immunized mice produced a polarized type 1 cytokine response when cultured in vitro with immunizing antigen (data not shown). Immune splenocytes or lymph node cells raised with $\mathrm{CW} / \mathrm{M}$ or YSP antigen passively transferred both DTH and resistance to infection (Figure 4, a and b). Lymph node cells from $\mathrm{CW} / \mathrm{M}$-immunized mice were most active and reduced lung CFU by nearly five logs compared with control cells.

$C D 4^{+} T$-cell lines reactive with $C W / M$ antigen transfer resistance in the presence of IFN- $\gamma$. Cell-mediated immunity is crucial for the development of acquired resistance to $B$. dermatitidis (18). From the results described here, we presumed that $\mathrm{CW} / \mathrm{M}$ reactive $\mathrm{T}$ cells in the lymph nodes, which make type 1 cytokines, contribute to vaccine-induced resistance. To explore this, we generated two T-cell lines reactive with $\mathrm{CW} / \mathrm{M}$ and analyzed their phenotype and function in vitro and in vivo. Both lines were found to be greater than $95 \%$ $\mathrm{CD}^{+} \mathrm{CD}^{+} \alpha \beta \mathrm{T}$ cells (data not shown), and each proliferated in response to antigen stimulation in vitro with $\mathrm{CW} / \mathrm{M}$ (Figure 5a). CW/M-Th2 cells released IL-4 in response to antigen stimulation, but no IFN- $\gamma$. CW/M-Th1 cells produced IFN- $\gamma$ in response to antigen stimulation, but no IL-4. After adoptive transfer, CW/M-Th1 cells reduced lung CFU 24-fold, compared with control (Figure $5 \mathrm{~b}$ ). In contrast, CW/M-Th2 cells led to a twofold increase in lung CFU. In a survival study, mice $(n=10)$ treated with CW/M-Th 1 cells survived a mean of $39 \pm 7$ days, whereas PBS-control-treated mice survived a mean of $22 \pm 4$ days $(P=0.001)$.

T-cell line transfers and preceding results illustrate that vaccine resistance correlates with IFN- $\gamma$ production in vitro. To provide firm evidence that IFN- $\gamma$ contributes to resistance in vivo, we treated vaccinated mice with anti-IFN- $\gamma \mathrm{mAb}$ throughout infection. IFN- $\gamma$ neutralization increased lung CFU 100 -fold at 2 weeks after infection, compared with rat IgG control (mean CFU 5,210 $\pm 4,500$ vs. $58 \pm 60$, respectively; $P=0.01)$. Nonvaccinated controls had a mean of $3,092,300 \pm 763,970$ lung CFUs. Thus, IFN- $\gamma$ is required for vaccine resistance, but not solely responsible, and other cytokine-dependent or -independent mechanisms are likely to contribute. 
$\mathbf{a}$

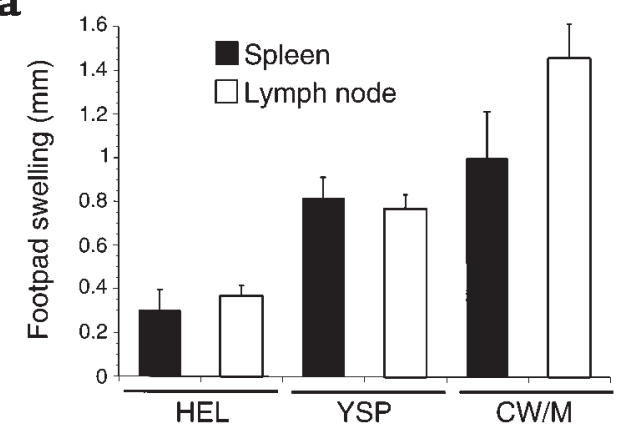

b

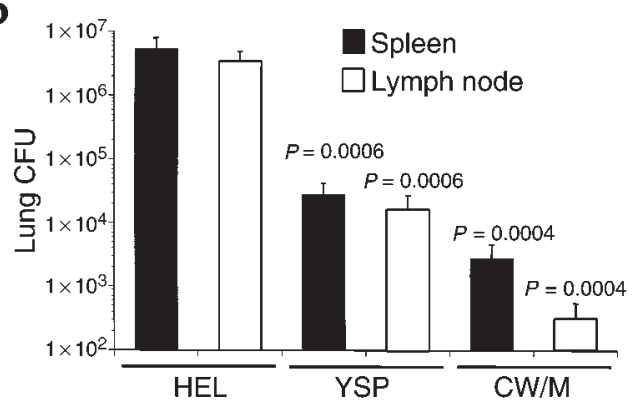

Figure 4

Adoptive transfer of DTH and resistance to $B$. dermatitidis by immune splenocytes and lymph node cells. Mice were immunized three times subcutaneously with strain no. 55 , and 2 weeks later, boosted with $\mathrm{CW} / \mathrm{M}$ or YSP antigen in CFA. As a control, mice were immunized three times with hen egg lysozyme (HEL) in Freund's. Ten days after immunization, cells were harvested and passively transferred into naive mice. (a) DTH. Two hours after transfer, two mice per group were injected with $10^{5}$ heat-killed yeast of strain no. 55 into one hind footpad and PBS into the other. Footpad swelling is depicted as mean \pm SEM. (b) Burden of lung infection. One day after transfer, groups of 10 mice were infected intratracheally with $2 \times 10^{2}$ yeast of wild-type strain 26199; they were analyzed for lung CFU 3 weeks later. $P$ values are in comparison to corresponding lymphoid populations of HEL controls.

\section{Discussion}

In people and animals, sporadically occurring pulmonary blastomycosis generally progresses and requires treatment to prevent a fatal outcome. Experimental infection in mice is uniformly lethal. We demonstrate here that resistance to pulmonary infection with $B$. dermatitidis can be achieved by immunization with a recombinant, live, attenuated strain of $B$. dermatitidis lacking the WI-1 adhesin. Live, attenuated viral vaccines have been used widely with great efficacy. Attenuated variants of fungi have been used previously to immunize against infection. An echinocandin-resistant variant of Candida albicans (PCA-2) vaccinates mice against infection with a nonisogenic wild-type virulent strain CA-6 (19). An attenuated variant of Trichophyton verrucosum has been used to vaccinate against ringworm in cattle (20). The genetic basis of attenuation has not been defined in either of these fungal vaccine variants. Spontaneous reversion may occur in such situations and raises concern about uncharacterized natural variants of fungi and other microbial pathogens. To our knowledge, we describe the first recombinant, attenuated vaccine against $B$. dermatitidis or other fungal pathogen.

In our study, the parental, wild-type strain ATCC 26199 was not suitable for vaccination. That strain disseminated from the skin injection site to the lung, where infection progressed. Morozumi et al. (21) reported that subcutaneous administration of live ATCC 26199 yeast protected mice against pulmonary blastomycosis. In contrast to our study, those authors reported that ATCC 26199 yeast injected subcutaneously into each of two sites was cleared by 4 weeks after injection. The discrepancy between their findings and ours might be explained by recent findings about spontaneous variation of ATCC strain 26199. Mutants of 26199 have arisen spontaneously by serial passage in vitro: ATCC 60915 is an attenuated mutant (22), and ATCC 60916 is avirulent (23). Phenotypic alterations recently documented in these mutants include partial or complete loss of surface $\alpha$-(1,3)-glucan (24) and changes in the amount of surface and secreted WI-1 (25). To guard against loss of pathogenicity in B. dermatitidis, including strain 26199 , we monitor virulence in mice and measure surface $\alpha$-(1,3)-glucan and WI-1

a

CW/M-Th1 line
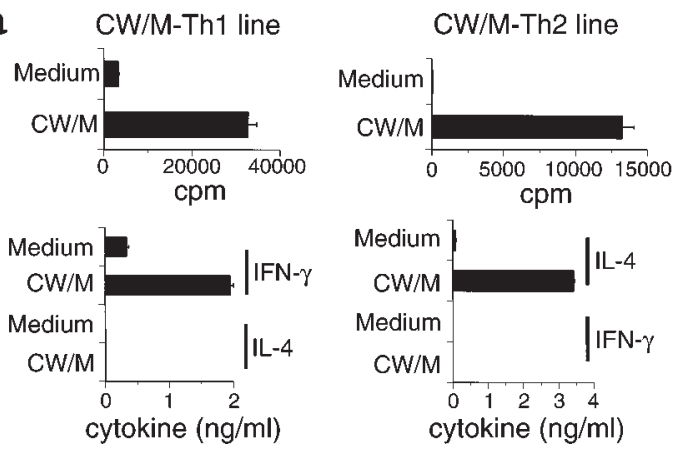

b

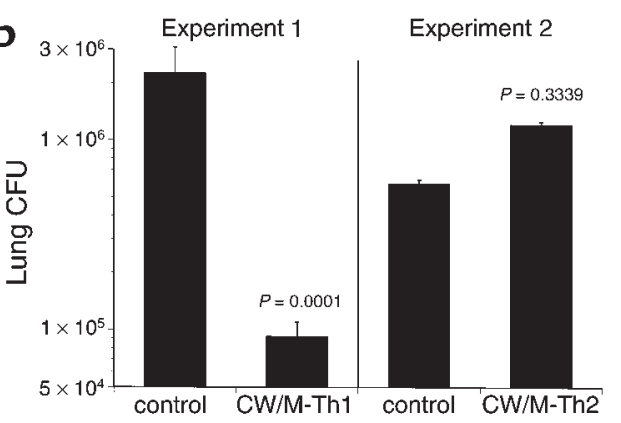

Figure 5

In vitro responses and in vivo function of T-cell lines with polarized cytokine phenotypes in response to $\mathrm{CW} / \mathrm{M}$ antigen from strain no. 55. (a) Proliferation and production of IFN- $\gamma$ and IL-4 by T-cell lines in vitro in response to stimulation with $\mathrm{CW} / \mathrm{M}$. Assays were performed as described in Figure 2. (b) Burden of lung infection after adoptive transfer of T-cell lines. A day after adoptive transfer of $T$ cells ( $10^{7}$ cells per mouse), animals ( $n=13$ per group) were infected intratracheally with $10^{2}$ yeast of wild-type strain 26199 . Controls received mock transfer with $\mathrm{PBS}$. Three weeks after infection, mice were analyzed for lung infection. Values are geometric mean CFUs \pm SEM. $P$ values are for comparison of mice that received a T-cell line versus those that did not. 
routinely during passage. We also discard isolates after eight to ten weekly passages in vitro. The wild-type strain 26199 used for vaccination by Morozumi et al. (21) appears to have mutated spontaneously and lost virulence, which could have escaped attention, as phenotypes associated with loss of virulence had not been delineated at that time. It should be emphasized that spontaneous attenuated mutants of dimorphic fungi are often unstable and frequently revert to the virulence phenotype after passage in serum in vitro or animals (26). This fact underscores the importance of using genetically defined and stable mutations for attenuated vaccine strains of dimorphic fungi, rather than spontaneous, uncharacterized mutants. Parenthetically, spontaneous variation does not account for loss of virulence of recombinant strain no. 55. Resupply of WI-1 in trans restores pathogenicity to strain no. 55, which establishes that loss of WI-1, not another defect, is responsible for loss of virulence (3).

Additional attributes make the recombinant, attenuated strain no. 55 a promising vaccine and source of protective antigens. Vaccination induced substantial resistance: lung CFU 2-3 weeks after infection was reduced by three or more logs; a majority of immunized mice survived a lethal challenge; and most surviving mice had sterilizing immunity. Importantly, vaccinated mice resisted a challenge with both the isogenic wild-type strain and nonisogenic strains from various geographical regions. Thus, vaccine strain no. 55 shares immunodominant, protective antigen(s) with nonisogenic strains of $B$. dermatitidis.

To pursue those protective antigens, we generated crude preparations from vaccine strain no. 55 and tested their capacity to vaccinate against experimental infection. Each of the three antigens (YSP, YCE, and $\mathrm{CW} / \mathrm{M}$ ) induced protective immunity. Complexity and protective efficacy of the antigens varied. CW/M is the most complex and protective one in lowering the burden of lung infection. The YSP antigen is the least complex and protective. Enhanced protective efficacy of $\mathrm{CW} / \mathrm{M}$ could be due to the presence of a greater number of protein antigens or of uniquely protective components. In a more chronic pulmonary infection, in which mice were infected with a lower inoculum and controls expired over a 2-month interval, YCE and $\mathrm{CW} / \mathrm{M}$ protected at least $70 \%$ of mice from death. A chronic infection may better resemble naturally occurring infection with $B$. dermatitidis and underscores the vaccine potential of the antigens. Gomez et al. (15) isolated CW/M antigen from Histoplasma capsulatum, which protects against lethal experimental histoplasmosis. HIS-62, or hsp 60, is a major component of $H$. capsulatum $\mathrm{CW} / \mathrm{M}$ and mediates protection $(27,28)$. Active components of $B$. dermatitidis $\mathrm{CW} / \mathrm{M}$ are under study.

To elucidate immune correlates of vaccine resistance, we compared the cytokine profiles of immunized, resistant mice and nonimmunized, susceptible mice. Production of type 1 cytokines in vitro was tightly linked with vaccine-induced resistance to $B$. dermatitidis in vivo. First, immunized, resistant mice produced IFN- $\gamma$ in response to in vitro antigen stimulation, whereas nonimmune, susceptible mice did not. Second, splenocytes and lymph node cells that adoptively transferred DTH and resistance exhibited polarized type 1 cytokine profiles in vitro. Third, protective efficacy after immunization with antigens correlated with IFN- $\gamma$ production by antigen-stimulated splenocytes in vitro. Fourth, protective immunity could be transferred with $\mathrm{CD}^{+} \mathrm{T}$ cells of a line only when they evinced a polarized type 1 cytokine profile. Last, and importantly, neutralization of IFN- $\gamma$ in vaccinated mice reduced control of infection 100-fold, offering direct evidence for participation of IFN- $\gamma$ in resistance. Thus, our results support the Th1/Th2 paradigm of immunity to medically important fungi, including B. dermatitidis (29-32).

A role for type 1 cytokine in vaccine immunity to $B$. dermatitidis is not unexpected, as IFN- $\gamma$ production is an established mechanism by which $\mathrm{T}$ cells enhance fungicidal activity of phagocytes (33). However, in our study, much greater resistance was transferred by immune splenocytes or lymph node cells than by $\mathrm{CD}^{+}$ T-cell lines. Neutralization of IFN- $\gamma$ also impaired, but did not abolish, vaccine immunity. Lymphocyte trafficking and incomplete neutralization could explain these respective results. However, other T-cell subsets or cytokines, or B-cells, in concert may also contribute to vaccine immunity and are being investigated (M. Wüthrich et al., manuscript in preparation).

\section{Acknowledgments}

This work was supported by grants AI40996 and AI35681 from the US Public Health Service (B.S. Klein) and by fellowship grant no. 823A-56729 from the Swiss National Science Foundation (M. Wüthrich). B.S. Klein is the recipient of a Research Career Development Award from the $\mathrm{NIH}$ and is a Burroughs Wellcome Fund Scholar in Molecular Pathogenic Mycology. We thank Bob Gordon for preparing illustrations and Lan Zheng and Michael Kosorok for statistical assistance.

1. Harvey, R.P., Schmid, E.S., Carrington, C.C., and Stevens, D.A. 1978. Mouse model of pulmonary blastomycosis: utility, simplicity, and quantitative parameters. Am. Rev. Respir. Dis. 117:695-703.

2. Wüthrich, M., Chang, W.L., and Klein, B.S. 1998. Immunogenicity and protective efficacy of the WI-1 adhesin of Blastomyces dermatitidis. Infect. Immun. 66:5443-5449.

3. Brandhorst, T.T., Wüthrich, M., Warner, T., and Klein, B. 1999. Targeted gene disruption reveals an adhesin indispensable for pathogenicity of Blastomyces dermatitidis. J. Exp. Med. 189:1207-1216.

4. Klein, B.S., and Jones, J.M. 1990. Isolation, purification, and radiolabeling of a novel 120-kD surface protein on Blastomyces dermatitidis yeasts to detect antibody in infected patients. J. Clin. Invest. 85:152-161.

5. Klein, B.S., Sondel, P.M., and Jones, J.M. 1992. WI-1, a novel 120-kilodalton surface protein on Blastomyces dermatitidis yeast cells, is a target antigen of cell-mediated immunity in human blastomycosis. Infect. Immun. 60:4291-4300.

6. Chang, W.L., et al. 2000. T-cell epitopes and human leukocyte antigen restriction elements of an immunodominant antigen of Blastomyces dermatitidis. Infect. Immun. 68:502-510.

7. Klein, B.S., Squires, R.A., Lloyd, J.K.F., Ruge, D.R., and Legendre, A.M. 2000. Canine antibody response to Blastomyces dermatitidis WI-l antigen. Am. J. Vet. Res. 61:554-558. 
8. Klein, B.S., et al. 1986. Isolation of Blastomyces dermatitidis in soil associated with a large outbreak of blastomycosis in Wisconsin. N. Engl.J. Med. 314:529-534.

9. Klein, B.S., Vergeront, J.M., DiSalvo, A.F., Kaufman, L., and Davis, J.P 1987. Two outbreaks of blastomycosis along rivers in Wisconsin. Isolation of Blastomyces dermatitidis from riverbank soil and evidence of its transmission along waterways. Am. Rev. Respir. Dis. 136:1333-1338.

10. Bakerspigel, A., Kane, J., and Schaus, D. 1986. Isolation of Blastomyces dermatitidis from an earthen floor in southwestern Ontario, Canada. J. Clin. Microbiol. 24:890-891.

11. Denton, J., and Di Salvo, A. 1964. Isolation of B. dermatitidis from natural sites in Augusta, Georgia. Am. J. Trop. Med. Hyg. 13:716-722.

12. Audet, R., Brandhorst, T.T., and Klein, B. 1997. Purification in quantity of the secreted form of WI-1: a major adhesin on Blastomyces dermatitidis yeasts. Protein Expr. Purif. 11:219-226.

13. Worsham, P.L., and Goldman, W.E. 1988. Quantitative plating of Histoplasma capsulatum without addition of conditioned medium or siderophores. J. Med. Vet. Mycol. 26:137-143.

14. Kruisbeck, A.M. 1992. Preparation of cell suspensions from spleen, thymus, and lymph node. In Current protocols in immunology. J.E. Coligan, A.M. Kruisbeck, D.H. Margulies, and W. Strober, editors. John Wiley \& Sons. New York, New York, USA. 3.1.3.

15. Gomez, A.M., Rhodes, J.C., and Deepe, G.S., Jr. 1991. Antigenicity and immunogenicity of an extract from the cell wall and cell membrane of Histoplasma capsulatum yeast cells. Infect. Immun. 59:330-336.

16. Fisher, L.D., and van Belle, G. 1993. Biostatistics: a methodology for the health sciences. John Wiley \& Sons. New York, New York, USA. 611-613.

17. Mantel, N., and Haenszel, W. 1959. Statistical aspects of the analysis of data from retrospective studies of disease. Journal of the National Cancer Institute. 22:719-748.

18. Cozad, G.C. 1992. Experimental blastomycosis. In Blastomycosis. Y. AlDoorey and A.F. DiSalvo, editors. Plenum Publishing Corp. New York, New York, USA. 221-236.

19. Romani, L., et al. 1992. Course of primary candidiasis in T cell-depleted mice infected with attenuated variant cells. J. Infect. Dis. 166:1384-1392.

20. Gudding, R., and Naess, B. 1986. Vaccination of cattle against ringworm caused by Trichophyton verrucosum. Am. J. Vet. Res. 47:2415-2417.

21. Morozumi, P.A., Brummer, E., and Stevens, D.A. 1982. Protection against pulmonary blastomycosis: correlation with cellular and humoral immunity in mice after subcutaneous nonlethal infection. Infect. Immun. 37:670-678.

22. Brass, C., et al. 1982. Spontaneous mutant of Blastomyces dermatitidis attenuated in virulence for mice. Sabourandia. 20:145-158.

23. Morrison, C.J., and Stevens, D.A. 1991. Mechanisms of fungal pathogenicity: correlation of virulence in vivo, susceptibility to killing by polymorphonuclear neutrophils in vitro, and neutrophil superoxide anion induction among Blastomyces dermatitidis isolates. Infect. Immun. 59:2744-2749.

24. Hogan, L.H., and Klein, B.S. 1994. Altered expression of surface alpha1,3 -glucan in genetically related strains of Blastomyces dermatitidis that differ in virulence. Infect. Immun. 62:3543-3546.

25. Klein, B.S., Chaturvedi, S., Hogan, L.H., Jones, J.M., and Newman, S.L. 1994. Altered expression of surface protein WI-1 in genetically related strains of Blastomyces dermatitidis that differ in virulence regulates recognition of yeasts by human macrophages. Infect. Immun. 62:3536-3542.

26. Hogan, L.H., Klein, B.S., and Levitz, S.M. 1996. Virulence factors of medically important fungi. Clin. Microbiol. Rev. 9:469-488.

27. Gomez, F.J., Allendoerfer, R., and Deepe, G.S., Jr. 1995. Vaccination with recombinant heat shock protein 60 from Histoplasma capsulatum protects mice against pulmonary histoplasmosis. Infect. Immun. 63:2587-2595

28. Gomez, F.J., Gomez, A.M., and Deepe, G.S., Jr. 1991. Protective efficacy of a 62-kilodalton antigen, HIS-62, from the cell wall and cell membrane of Histoplasma capsulatum yeast cells. Infect. Immun. 59:4459-4464.

29. Romani, L., and Kaufmann, S.H. 1998. Immunity to fungi: editorial overview. Res. Immunol. 149:277-281.

30. Romani, L. 1997. The T cell response against fungal infections. Curr. Opin. Immunol. 9:484-490.

31. Brummer, E., Hanson, L.H., and Stevens, D.A. 1993. IL-4, IgE, and interferon-gamma production in pulmonary blastomycosis: comparison in mice untreated, immunized, or treated with an antifungal (SCH 39304). Cell. Immunol. 149:258-267.

32. Murphy, J., Friedman, H., and Bendinelli, M. 1993. Fungal infections and immune responses. Volume 19. Plenum Press. New York, New York, USA. 574 pp.

33. Kullberg, B.J., and Anaissie, E.J. 1998. Cytokines as therapy for opportunistic fungal infections. Res. Immunol. 149:478-488. 